\title{
Brief Communication: The dark side of risk and crisis communication: legal conflicts and responsibility allocation
}

\author{
A. Scolobig \\ Climate Policy Group; Department of Environmental Systems Science, ETH-Swiss Federal Institute of Technology, \\ Zurich, Switzerland
}

Correspondence to: A. Scolobig (anna.scolobig@usys.ethz.ch)

Received: 11 March 2015 - Published in Nat. Hazards Earth Syst. Sci. Discuss.: 20 April 2015

Revised: 22 June 2015 - Accepted: 26 June 2015 - Published: 30 June 2015

\begin{abstract}
Inadequate, misinterpreted, or missing risk and crisis communication may be a reason for practitioners, and sometimes science advisors, to become the subjects of criminal investigations. This work discusses the legal consequences of inadequate risk communication in these situations. After presenting some cases, the discussion focuses on three critical issues: the development of effective communication protocols; the role, tasks, and responsibilities of science advisors; and the collateral effects of practitioners' defensive behaviours. For example, if the avoidance of personal liability becomes a primary objective for practitioners, it may clash with other objectives, such as the protection of vulnerable communities or the transparency of decision making. The conclusion presents some ideas for future research on the legal aspects of risk communication.
\end{abstract}

\section{Introduction}

Ineffective, inadequate, misinterpreted, or missing risk and crisis communication may be a reason for risk and emergency managers to be summoned to court and become the subjects of criminal investigations. For example, in 2013 the mayor of Sarno, a town in southern Italy hit by a landslide in 1998, was sentenced to 5 years in prison and interdiction from public office because he did not issue an evacuation order. More precisely, he failed to provide adequate information that could otherwise have saved many lives, or so the legal argument goes (Corriere del Mezzogiorno, 2013).

This is not a unique example. Several authors maintain that there is a growing trend of legal conflicts regarding the allocation of responsibility for disaster risk management, or even an over criminalisation of civil protection officers (Cedervall Lauta, 2015; DPCM and CIMA, 2013; Sterett, 2013; Altamura et al., 2011). This trend may have several collateral effects that will be described in the following sections. The focus of this work is on the legal consequences of official communication and how the fear of these consequences affects risk and emergency managers' attitudes, behaviours, and decisions. One critical point is whether the allocation of responsibility may influence what managers, public authorities, and science advisors decide to communicate, what information they provide, how they define known and unknown factors, how they communicate these factors, and to whom and when such information is provided.

So far, most of the literature on risk and crisis communication has focused on: (i) the disconnect in the risk perceptions of experts and lay people (e.g. Otway and Wynne, 1989; Fischhoff, 1995, 2013); (ii) the need to foster two-way communication processes (e.g. De Marchi, 1995; Kasperson, 2014); (iii) the improvement of information credibility, saliency, and legitimacy (e.g. Cash et al., 2003); (iv) the role of social trust and other variables in influencing communication processes, and more recently (e.g. Siegrist, 2014); (v) on strategies to provide useful information about scientific uncertainty, especially in the context of climate change (e.g. Patt and Weber, 2014; Geller, 2015; Albarello, 2015).

The relationship between communication practices and responsibility distribution so far has not captured much attention from researchers. Diagnostic tools have been designed in order to detect and rank the different types of uncertainties, which includes legal uncertainty, affecting risk and crisis communication and management (e.g. De Marchi, 1995; Van Der Sluijs et al., 2005). Despite this, the applications of 
these tools to analyse legal uncertainty in the sector of natural hazards has been limited. More generally, while a great deal of attention has been focused on scientific uncertainties and their quantification, the same is not true for the analysis of legal uncertainties and of the interactions between different types of uncertainties, such as legal, social, scientific, etc.

This lack of research inhibits the comparison of different experiences, the identification of hallmarks of good practices as well as of the core attributes of the actors within them.

This brief communication begins by describing some examples where risk and/or emergency managers, scientific advisors, or local authorities became the subjects of criminal investigations or had to go to court. The objective is not to provide a detailed description of the legal cases, but to highlight the critical points and main lessons for risk communication and management that are implicit in the experience. Where there is available data, the discussion includes what lessons have been learned, by whom, and what has changed afterwards.

The four examples provide the groundwork for our discussion about the development of effective communication protocols; the role, tasks, and responsibilities of science advisors; and the dangers of overcriminalisation of civil protection officers. The conclusion presents some ideas for a new research agenda on the legal aspects of risk communication, highlighting topics that deserve further reflection and analysis.

\section{The legal implications of risk and crisis communication}

Inadequacies in risk and crisis communication can have devastating consequences, the worst being the preventable loss of life. In addition to this, further legal, economic, and social consequences, such as legal conflicts and trials, increased damage to buildings or infrastructures due to missing information, inadequate individual and community preparedness due to lack of information etc., should not be underestimated (del Carmen Llasat and Siccardi, 2010).

As already mentioned above, the focus of this work is on the legal consequences, which often influence the attitudes and behaviours of local authorities and civil protection officers. In this respect the critical issues are the responsibility attribution for alarms, zoning decisions, enforcement of building codes, and decisions concerning compensation and assistance. The four examples described in this section deal with these issues.

In 2013 the mayor of Sarno, a town in southern Italy, was sentenced to 5 years in prison and interdiction from public office because he did not give an evacuation order 15 years before, in the year 1998 when a landslide occurred. In the case of floods or landslides similar to the one in Sarno, Italian legislation maintains that once the mayor has received notice of a threshold being overcome from the authorities in charge (usually the Region or the Prefect), it is up to him or her to declare the corresponding alert level after an internal consultation with the responsible persons of the Municipal Civil Protection (law 225/1992; law 100/2012). More precisely, in Italy the activation of the various phases of the emergency plans is the task of the President of the Regional Council or his/her delegates (prefects, mayors, etc.). It also depends on the type of event (A, B or C - increasing in magnitude). If it is a type A event, as in the case of Sarno, once the mayor has received notice of a threshold being overcome from the authorities in charge (usually the Region or the Prefect), it is up to him or her to declare the corresponding alert level after an internal consultation with the responsible persons of the Municipal Civil Protection. If it is a type B or C event, it is the Prefect (in cooperation with the President of the Region, the mayors etc.) who is in charge of the coordination of the emergency activities (law 225/1992; law 100/2012).

In Sarno, in the year 1998 more than 100 shallow landslides were triggered during approximately $16 \mathrm{~h}$ of rainfall along the slopes (Cascini, 2004 2005), killing a total of 159 people in four towns located at the toe of the massif. Of the four towns the most heavily affected was Sarno.

One of the problematic issues discussed during the trial was the legal obligation of the mayor to (i) inform the population about the risk and (ii) evacuate the area (DPCM and CIMA, 2013). More precisely the defense and the prosecution were arguing whether (i) the mayor provided (or not) reassuring information to the residents; (ii) if he had enough knowledge to provide information; and (iii) if he (and not the prefect) was the one in charge of providing such information. As in many other legal cases, the critical point was the causal link between the statements of those in charge and the residents' behaviours, including what evidence should be used to prove this link (ibidem). Did residents stay at home because the mayor did not give the warning? How many people could have been saved if he had given the warning?

Another example is the Xynthia storm, which hit the west coast of France in 2010. When the storm burst seawalls in the town of La Faute-sur-mer in the Vendée region on the night of 28 February, many of those who were killed (29 persons in total) were still asleep. 28 victims were in a 3 ha area labelled the bowl of death by the media, as well as by political authorities (UNISDR, 2015). Most of the victims were unaware that their homes were built in areas at high risk of flooding. Relatives of the victims wanted to know who allowed homes to be built in such dangerous areas, why the residents had not been appropriately informed about the risk, and why no proper flood warnings were issued.

In the year 2014, the prosecutor identified excessive urbanisation as a reason for the high losses and attributed responsibility to the mayor and the deputy mayor. As reported in the Global Risk Assessment Report of the United Nations, "Flood risk in the area was known to be high, but risk information had been hidden deliberately by the authorities to 
allow the construction of more than 200 new dwellings in flood prone areas" (ibidem: 126).

At the time of writing, the mayor of the town has been sentenced to 4 years in jail. One of the science advisors of the mayor is also on trial for failing to alert him that a dangerous storm was imminent.

Another example regards a heavily reported and still at the time of writing ongoing legal case in which scientific advisors have played a critical role. The case is related to an earthquake that struck the city of L'Aquila and its province in central Italy on 6 April 2009. It involves seven experts convened by the head of Civil Protection for a meeting of the Major Risk Commission, an advisory body of the National Civil Protection Department which has the duty of evaluating the risk associated with situations such as earthquakes and of providing expert opinions (Cocco et al., 2015). More precisely, the Major Risk Commission activities are of a technoscientific and advisory type and include providing guidance in connection with the forecast and prevention of the different risk situations.

At the centre of this case is the crisis communication process and the way in which information had been conveyed to the local population. Highlighting this is the claim made by some people (either people who had been injured or relatives of some of the victims) 6 days after the earthquake that the injuries and deaths occurred because the victims had failed to enact the usual precautionary measures due to the official reassurance they had received from the competent authorities. Since then, there has been a first level judgment and an appeal. At the end of the first level trial (in 2012) the Court of L'Aquila sentenced the seven defendants to 6 years in prison and required them to make huge compensation payments to the victims and/or their relatives for multiple counts of manslaughter and injuries. At the end of the appeal trial (2014) all but one defendant, the then deputy director of the Department of Civil Protection, were cleared. A third Court judgement (called Corte di Cassazione) is pending.

This case is very complex and has been interpreted in many different ways: a lawsuit against science, a failure to predict earthquakes, a failure in risk communication, and a sign of jurists' ignorance about scientific uncertainty and probability are some examples of the interpretations of the L'Aquila case in the national and international press (Ropeik, 2012; Hall, 2011; Nosengo, 2010; Aspinall, 2011; Mucciarelli, 2015). Most of the discussions at the hearings revolved around who was responsible for communicating what to whom, and how and when the available knowledge was communicated. A critical issue was the mandate of the members of the Italian Major Risk Commission, which had to not only provide advice, but also communicate that advice to the public. Indeed the aims of the meeting, as established by the then Head of the National Civil Protection were to: (i) provide an objective evaluation of the seismic events, also in relation to what can be forecasted; and (ii) discuss and provide advice about the warnings (Presidenza del Consiglio dei Min- istri 2009). Moreover, as reported in the first verdict of the Court of L'Aquila, "the Commission, due to a pre-established [by the head of the National Department of Civil Protection] communication strategy, was not addressing its advice to the Civil Protection Department, but directly to the population" (Tribunale di L'Aquila n. 380/2012: p. 175).

The seven defendants were asked to provide suggestions not only on scientific issues but also on decision making and, indirectly, on behaviours that the population should have enacted. This case shows that even if the legislation clearly distinguishes the role of the scientific advisors from decision makers, the boundary between the responsibility for provision and the communication of scientific information can be easy to cross (Scolobig et al., 2014b). As Cocco et al. (2015) emphasise, the role of the journalists has been considerably downplayed in the commentaries on the L'Aquila case: unclear, ambiguous, and inconsistent messages disseminated by the mass media confused the citizens, sometimes even altering the understanding of information provided by other sources (see also Amato et al., 2015).

The last example is about the fear of the legal implications of crisis communication and related social side effects. Between 2006 and 2009, the percentage of false positive meteohydrogeological alerts issued in Italy rose from 37 to $65 \%$ (Altamura et al., 2011).

Several authors argue that the key reasons are not to be found in a rapid increase in meteorological events, but rather in the increase of legal cases involving the authorities in charge of issuing the warning (DPCM and CIMA, 2013; Altamura et al., 2011). In order not to face legal charges in case of a missed alarm, emergency managers adopted selfprotective behaviours by issuing a larger number of false positive alerts. Rather than relying on their own evaluation and judgment of the situation, they used the automated thresholdalert as a procedural constant. This resulted in the issuing of a larger number of alerts which augmented the percentage of false positives. The collateral effects of false positives are unfortunately well known: the greater the residents' experience of false positives, the less residents tend to respond to a warning (for a literature review see Sharma and Patt, 2012).

\section{Discussion}

The cases described in Sect. 2 highlight critical issues at the interface of scientific, communication, and legislative aspects. This section discusses three of those issues in more detail: the development of effective communication protocols; the role, tasks, and responsibilities of science advisors; and the side effects of defensive behaviours of risk and emergency managers. 


\subsection{Effective communication protocols}

After the L'Aquila earthquake described in Sect. 2, several authors criticised the lack of protocols for providing scientifically based advice and communicating risk to the population (Marzocchi, 2012; Jordan et al., 2011). Others highlighted the need for a new code of ethics regarding media reporting concerning disasters and natural hazards (Papadopoulos, 2015).

From the legal perspective these protocols, which are often included in municipal emergency plans, are considered a way to communicate with citizens, to clarify responsibility distribution and, ultimately, to prevent the civil protection officers' involvement in criminal law proceedings. This means that, in the case of hydro-meteorological events for example, rainfall thresholds are identified and a monitoring system is put in place (nowadays often based on weather radar and able to provide nowcasts). When the thresholds are exceeded, civil protection managers have to alert the local authorities and/or the population by using appropriate messages and communication strategies. On the other hand exceeding such a threshold does not always imply the automatic release of an alert, which is dependent on the experts and local authorities' evaluation - often done on a case by case basis. This subjective evaluation is one of the reasons why setting up effective communication protocols is not a simple task. However, the other option of taking the automated threshold-alert as a procedural constant may have some negative side effects, for example an increasing number of false alerts (as described in the case of meteo-hydrogeological alerts in Italy in Sect. 2). Is the automated threshold alert the only way to guarantee legal protection for those in charge of issuing an alert? What are the alternatives?

Making residents more responsible for their decisions about evacuation may be one alternative. This is in line with the call for people-centred warning systems (Oxley, 2013; Basher, 2006) and new approaches in which the public is conceived of as a central element and resource in disaster risk management. These approaches are based on the assumption that involving people in decisions and actions is empowering (thereby encouraging ownership, responsibility, and participation), and results in more effective disaster risk reduction processes. Practitioners and local authorities should not only involve the public as partners but also share their decision making power with the public by taking into account their needs and perspectives. In order to motivate people to proactively contribute to risk and emergency management, longterm processes are needed as well as a clear identification of the benefits for participants. Tax reduction or lower insurance premiums are some examples (Scolobig et al., 2015).

New information and communication technologies, social media and mobile phone applications may empower people and allow them to access information about hazard and/or risk assessment or to check evacuation routes or shelter locations. For example with the help of new social media, crowd- sourced, self-organised approaches to disaster relief are proving to be faster and more effective than centralised governmental responses (Scolobig et al., 2015). Therefore the potential of new technologies should be considered in order to improve communication protocols.

The implications in terms of responsibility distribution, especially between residents, authorities, and those in charge of providing information through social media (i.e. journalists), should be also taken into account. For example the L'Aquila case described in Sect. 2 shows how the boundaries of responsibility allocation for provision of information are easy to cross.

Nevertheless, residents' response to alert and warning remains a critical point in the information chain. The identification of who is going to receive the warning, as well as how this person is going to react to it, are among the most delicate issues. Research results show very low percentages of households that actually receive official (institutional) warnings. For example, in the case of floods in the UK and Germany, only around $50 \%$ of survey respondents stated that they have received an official warning (Kuhlicke et al., 2011). The ratio is even worse in the case of typhoons, with percentages dropping to less than $14 \%$ in the case of typhoon Morakot in Taiwan, 2009 (Luo et al., 2014). Notwithstanding these low percentages, in some countries mayors can be sentenced to jail for not having issued the official warning, as shown by the case of Sarno and Xynthia.

Finally, to improve communication protocols, it is crucial not only to identify the best way to communicate information about the alert and scientific uncertainty, but also to set appropriate responsibility frameworks. Better strategies should be identified in order to inform people about the precautionary actions to undertake as well as the risks, benefits, and costs of their decisions, thereby allowing them to make sound and responsible choices for self-protection in case of danger (Scolobig et al., 2014b).

\subsection{The unclear tasks and responsibilities of science advisors}

Unclear and overlapping roles and responsibilities are often a critical problem in emergency management as identified, for example, after hurricane Katrina in 2005 (White House, 2006) and after many other events. The Xynthia and L'Aquila cases, described in Sect. 2, point out the need to re-discuss the role, tasks, and responsibilities of scientists and experts, whose advice contributes to and often influences decisions. However, the challenges at the interfaces of science, communication, and decision making are manifold.

Firstly, a critical point is the distinction between informing and making decisions. There is a clear difference between communication for decision making and research purposes (De Marchi, 2013, 2014, 2015). Providing simple and consistent information based on robust and established scientific evidence is often essential for communicating relevant infor- 
mation to the public (e.g. earthquakes cannot be predicted). On the other hand, providing detailed information about cutting edge new research results and related uncertainties is essential for disseminating research to the peer community (e.g. there is contradictory evidence about the role of seismic swarms as precursors of major earthquakes). Yet this problem highlights a sometimes inadequate reflection on the impact of science in society. So far the general view, among scientists, has been that doing science is one thing and communicating is another (Oreskes, 2015). Cases like L'Aquila or new disciplines like geoethics (Wyss and Peppoloni, 2015) show that the inter-relationship between knowledge, safety, and society is not easily disentangled: ethics, value, monetary, and social costs need to be considered to improve risk decision-making.

Secondly, it is not easy to deal with knowledge in contested terrains (Thompson, 2008) where different experts provide different framings of the same problem and therefore different solutions. How does one decide which one is the best (or the most desirable one from a social perspective) from a decision making perspective? As pointed out by Gluckman, "Science advice is not generally a matter of dealing with the easy issues that need technical solutions. Rather it is largely sought in dealing with sensitive matters of high public concern and inevitably associated with uncertainty and considerable scientific and political complexity" (Gluckman, 2014, p. 4). The decision maker (be it the mayor or somebody else) is therefore in the difficult position of having to deal with and communicate uncertain information. There is a vast literature on the communication of uncertainties related to natural hazards and climate change (e.g. Cash et al., 2006; Patt and Weber, 2014). In all of it though, one main dilemma emerges: is the role of scientific advice to provide information about the present state of knowledge in a specific disciplinary field and find the best way to communicate (scientific) uncertainty to the lay public? Or is their role to provide an informed opinion and different options, balancing evidence, uncertainties, institutional, legal and social contextual factors? In other words: should scientists be advocates of one solution or honest brokers of different options and related trade-offs? (Jasanoff, 2004, 2005; Gluckman, 2014; Pielke, 2007; Funtowicz, 2013). In the sector of natural risk management, the model of science advocacy is still mainstream and has hardly been questioned. Yet new disciplines such as geoethics question monolithic views about scientific advice and maintain, among other things, that "scientists are in charge of stating what alternative exist and what the degree of belief associated to each of them is" (Albarello, 2015, p. 6).

Thirdly, there are the challenges related to the different types of knowledge and expertise that might be helpful for attaining a broader and more accurate perspective of what the problem at hand is and how it should be managed. This often implies the involvement of experts with different disciplinary backgrounds. For example, in the case of warning systems and emergency management, scientific and social aspects are strongly interlinked. A precautionary approach will lead to more false alarms, which may have collateral social side effects, such as more anxiety and worries for residents and more uncertainty on what to do and how to respond to warnings (e.g. in case of seismic swarms that can last for months). Interdisciplinary knowledge should be generated in order to improve risk and crisis management.

A fourth challenge is that the divergent objectives of the scientists, the decision makers, and journalists should be carefully taken into account especially for what concerns communication activities, as shown for example in the L'Aquila case (Sect. 2). The main objective of journalists is to inform the population and create the news, i.e. report on sensational, relevant, interesting, new information that catches readers' attention, is relevant in their daily life and ultimately will increase the sales of the newspaper or will improve its reputation, etc.

The main objective of scientists is to achieve and publish new research results and develop new theories or methodologies that do not necessarily have direct application for decision-making. The main objective of practitioners is to reduce risk and avoid human life losses, but also to fulfil legal requirements by using effective and simple methodologies and to avoid liability in case of human life losses or damages. Research results show that reciprocal expectations of scientists and practitioners can be distorted by difficulties in making science useful for practitioners, because of the differences in mandates and missions, objectives, and organisational cultures between scientific and institutional communities (Scolobig et al., 2014a). For example practitioners often lament that the solutions proposed by scientists are either too generic to provide a really useful contribution or are technically and/or economically unfeasible (Dolce and Di Bucci, 2015).

If we accept that continuing to develop new theories and methodologies is vital for the progress of science, it can be argued that this does not always improve the quality and effectiveness of decision making or communication (Sharma et al., 2012). Indeed different methodologies may lead to different results as a starting point for decision making. For example, in the case of risk zoning, inconsistent scientific results obtained by using different methodologies can become legal proofs in the court in the case of decisions about building constraints (and related permits to build or not to build in a risky area). Thus, these scientific results can even become detrimental for practitioners.

The challenges described above clearly show that the role and connected responsibilities of scientific advice in crisis and emergency management still remain unsolved. 


\subsection{Defensive behaviours of risk and emergency managers}

"In recent years we have seen more legal conflicts regarding the allocation of legal responsibility in the aftermath of natural disasters and this trend seems only to be accelerating" (Cedervall Lauta, 2015, p. 4). Among other factors, this trend highlights the need to find better ways of protecting the rights and interests of risk-emergency managers, as well as those of the communities at risk, the victims of disasters and their relatives (del Carmen Llasat and Siccardi, 2010).

The problem is that the protection of different groups may often generate clashes of rights and interests. For example, if the avoidance of personal blame and liability becomes a primary objective of risk and emergency managers (see the case of increased percentage of meteo-hydrogeological alerts in Sect. 2), one may question whether it clashes with other objectives, such as the actual protection of vulnerable communities, the improvement of organisational standards or the transparency of decision-making and communication. The clash between different competing objectives and related trade-offs has already been researched in other sectors different from disaster management. For example research about the communication between medical doctors and patients clearly shows the trade-offs between doctors' self-protecting behaviours (to avoid liability) and the suggestions of the best treatment for patients' health (Kessler and McClellan, 1996; Studdert et al., 2005). This practice has been called defensive medicine, in which "physicians order tests and procedures primarily because of fear of malpractice liability" (Klingman et al., 1996). Some authors argue that, at the systemic level, this can generate inefficiencies much larger than the costs of compensating malpractice claimants (Kessler and McClellan, 1996).

Another example of collateral side effects of blame avoidance is the lack of self-reporting in case of mistakes or near misses that have not been detected by other members of the organisation or the public - depending on the context. It is not difficult to imagine that this can hinder organisational learning in the long term.

Therefore, if the trend of legal conflicts continues to grow, in the future we may expect not only an increase in the defensive behaviour of risk and emergency managers, but also more requests for insurance coverage in case of mistakes, which may raise costs and generate further stress on already limited resources.

\section{Conclusions}

This brief communication has discussed the legal implications of risk and crisis communication. Rather than providing a detailed description of the legal conflicts regarding the allocation of responsibility in risk and crisis management, the focus has been on the interface between legislative and communicative aspects.

Two points seem particularly critical: first, that scientific advice, its role, tasks, and connected responsibilities in crisis management need further scrutiny. Second, that the defensive and self-protective behaviours of risk and emergency managers can have dangerous social side effects. The development of new communication protocols can only partially solve these problems, especially if not matched with transformative changes in the institutional and legislative frameworks. Therefore, there is a need for a new research agenda on the legal aspects of risk communication. This includes the role of scientific advice under different legal and organisational schemes and, more generally, a discussion about responsibility distribution. In order to better protect the rights and interests of risk-emergency managers and of the communities at risk, more research should be done to compare and contrast experiences and identify the hallmarks of new models.

Acknowledgements. This brief communication benefited from the discussions held during a seminar at Bocconi University, Department of Law, Milan, Italy. My presentation, with contributions from Bruna De Marchi (Centre for the Study of the Sciences and the Humanities, University of Bergen, Norway), was entitled "Natural risk management after the L'Aquila case: What are the implications?". I deeply thank Bruna De Marchi, the seminar participants and the organiser, Giovanni Tuzet, Associate Professor of Legal Philosophy at Bocconi University, for the inspiring discussions, sharp insights and inputs. I also thank my colleague, Johan Lilliestam, for his precious comments on the first draft.

Edited by: F. Guzzetti

Reviewed by: K. Fleming and another anonymous referee

\section{References}

Albarello, D.: Communicating uncertainty: managing the inherent probabilistic character of hazard estimates, in: Geoethics: The Role and Responsibilities of Geoscientists, Special Publications, edited by: Peppoloni, S. and Di Capua, G., Geological Society, London, 1-6, 2015.

Altamura, M., Ferraris, L., Miozzo, D., Musso, L., and Siccardi, F.: The legal status of Uncertainty, Nat. Hazards Earth Syst. Sci., 11, 797-806, doi:10.5194/nhess-11-797-2011, 2011.

Amato, A., Cerase, A., and Galadini, F.: Terremoto, comunicazione, diritto: riflessioni sul processo alla Commissione Grandi Rischi, Franco Angeli, Milano, 2015.

Aspinall, W.: Check your legal position before advising others, Nat. Commun., 477, 251, doi:10.1038/477251a, 2011.

Basher, R.: Global early warning systems for natural hazards: systematic and people-centred, Philis. T. Roy. Soc., 364, 2167-2182, 2006.

Cascini, L.: The flowslides of May 1998 in the Campania region, Italy: the scientific emergency management, Ital. Geotech. J., 2, 11-44, 2004. 
Cascini, L.: Risk assessment of fast landslides. From theory to practice, in: Proceedings of the International Conference on "Fast Slope Movements - Prediction and Prevention for Risk Mitigation”, edited by: Cascini, L., Patron Editore, Bologna, 33-52, 2005.

Cash, D. W., Clark, W. C., Alcock, F., Dickson, N. M., Eckley, N., Guston, D. H., Jäger, J., and Mitchell, R. B.: Knowledge systems for sustainable development, P. Natl. Acad. Sci., 100, 80868091, doi:10.1073/pnas.1231332100, 2003.

Cash, D. W., Jonhatan, B., and Anthony, P.: Countering the 'loading dock' approach to linking science and decision making: a comparative analysis of ENSO forecasting systems, Sci. Technol. Human Val., 31, 465-494, 2006.

Cedervall Lauta, K.: Disaster law, Routledge, New York, 2015.

Cocco, M., Cultrera, G., Amato, A., Braun, T., Cerase, A., Margheriti, L., Bonaccorso, A., Demartin, M., De Martini, P., Galadini, F., Meletti, C., Nostro, C., Pacor, F., Pantosti, D., Pondrelli, S., Quareni, F., and Todesco, M.: The L'Aquila trial, in: Geoethics: The Role and Responsibilities of Geoscientists, Special Publications, edited by: Peppoloni, S. and Di Capua, G., Geological Society, London, 1-14, 2015.

Corriere del Mezzogiorno: Alluvione di Sarno, dopo quindici anni confermata la condanna del sindaco Basile, Newspaper article, http://corrieredelmezzogiorno.corriere.it (last access: 15 June 2015), 2013.

del Carmen Llasat, M. and Siccardi, F.: A reflection about the social and technological aspects in flood risk management - the case of the Italian Civil Protection, Nat. Hazards Earth Syst. Sci., 10, 109-119, doi:10.5194/nhess-10-109-2010, 2010.

De Marchi, B.: Uncertainty in Environmental Emergencies: A Diagnostic Tool, J. Conting. Crisis Manage., 3, 103-112, doi:10.1111/j.1468-5973.1995.tb00062.x, 1995.

De Marchi, B.: La sentenza di l'Aquila riaccende il dibattito sul rapporto tra scienza e potere politico, Epidemiol. Prev., 37, 8991, 2013.

De Marchi, B.: Scientific Advice and the Case of the L'Aquila Earthquake, Technikfolgenabschätzung, 3, 90-94, 2014.

De Marchi, B.: Risk Governance and the integration of scientific and local knowledge, in: Risk Governance, The articulation of hazard, politics and ecology, edited by: Fra Paleo, U., Springer, Berlin, 2015.

Dolce, M. and Di Bucci, D.: Risk management: roles and responsibilities in the decision making process, in: Geoethics: Ethical Challenges and Case Studies in Earth Science, edited by: Wyss, M. and Peppoloni, S., Elsevier, Waltham, Massachusetts, 211221, 2015.

DPCM, CIMA, Foundation: La Protezione Civile nella societá del rischio. Procedure, garanzie, responsabilitá, ETS, Pisa, 2013.

Fischhoff, B.: Risk Perception and Communication Unplugged: Twenty Years of Process1, Risk Analysis, 15, 137-145, doi:10.1111/j.1539-6924.1995.tb00308.x, 1995.

Fischhoff, B.: The sciences of science communication, P. Natl. Acad. Sci., 110, 14033-14039, doi:10.1073/pnas.1213273110, 2013.

Funtowicz, S. R. J.: Post-Normal Science, The Encyclopedia of Earth, http://www.eoearth.org/article/Post-Normal_Science, last access: 31 July 2013.

Geller, R. J.: Geoethics, Risk-Communication, and Scientific Issues in Earthquake Science, in: Geoethics: Ethical Challenges and Case Studies in Earth Science, edited by: Wyss, M. and Peppoloni, S., Elsevier, Waltham, Massachusetts, 263-272, 2015.

Gluckman, P.: The art of science advice to government, Nature, 507, $163-165,2014$.

Hall, S.: Scientists on trial: At fault?, Nature, 477, 264-269, 2011.

Jasanoff, S. (Ed.): The idiom of co-production, in: States of Knowledge: The Co-production of Science and Social Order, Routledge, London, 1-13, 2004.

Jasanoff, S.: Designs on Nature: Science and Democracy in Europe and the United States, Princeton University Press, Princeton, NJ, 2005.

Jordan, T., Chen, Y., and Gasparini, P. E. A.: Operational Earthquake Forecasting - State of Knowledge and Guidelines for Utilization, Report by the International Commission on Earthquake Forecasting for Civil Protection, Ann. Geophys., 54/4, 314-391, doi:10.4401/ag-5350, 2011.

Kasperson, R.: Four questions for risk communication, J. Risk Res., 17, 1233-1239, doi:10.1080/13669877.2014.900207, 2014.

Kessler, D. and McClellan, M.: Do Doctors Practice Defense Medicine?, Quart. J. Econ., 111, 353-390, 1996.

Klingman, D., Localio, A., Sugarman, J., Wagner, J., Polishuk, P., Wolfe, L., and Corrigan, A.: Measuring Defensive Medicine Using Clinical Scenario Surveys, J. Health Polit. Policy Law Sum., 2, 185-220, 1996.

Kuhlicke, C., Steinführer, A., Begg, C., Bianchizza, C., Bründl, M., Buchecker, M., De Marchi, B., Di Masso Tarditti, M., Höppner, C., Komac, B., Lemkow, L., Luther, J., McCarthy, S., Pellizzoni, L., Renn, O., Scolobig, A., Supramaniam, M., Tapsell, S., Wachinger, G., Walker, G., Whittle, R., Zorn, M., and Faulkner, H.: Perspectives on social capacity building for natural hazards: outlining an emerging field of research and practice in Europe, Environ. Sci. Policy, 14, 804-814, doi:10.1016/j.envsci.2011.05.001, 2011.

Luo, Y., Shaw, R., Lin, H., and Joerin, J.: Assessing response behaviour of debris-flows affected communities in Kaohsiung, Taiwan, Nat. Hazards, 74, 1429-1448, doi:10.1007/s11069-0141258-5, 2014.

Marzocchi, W.: Putting science on trial, Physics World, December 2012, 17-18, 2012

Mucciarelli, M.: Some comments on the first degree sentence of the "L'Aquila trial", in: Geoethics: Ethical Challenges and Case Studies in Earth Science, edited by: Wyss, M. and Peppoloni, S., Elsevier, Waltham, Massachusetts, 205-210, 2015.

Nosengo, N.: Italy puts seismologists on the dock, Nature, 465, 992, doi:10.1038/465992a, 2010.

Oreskes, N.: How earth science has become a social science, Hist. Social Res., 40, 246-270, 2015.

Otway, H. and Wynne, B.: Risk Communication: Paradigm and Paradox, Risk Analysis, 9, 141-145, doi:10.1111/j.15396924.1989.tb01232.x, 1989.

Oxley, M. C.: A "People-centred Principles-based" postHyogo framework to strengthen the resilience of nations and communities, Int. J. Disast. Risk Reduct., 4, 1-9, doi:10.1016/j.ijdrr.2013.03.004, 2013.

Papadopoulos, G. A.: Communicating to the general public earthquake prediction information: lessons learnt in Greece, in: Geoethics: Ethical Challenges and Case Studies in Earth Science, edited by: Wyss, M. and Peppoloni, S., Elsevier, Waltham, Massachusetts, 223-237, 2015. 
Patt, A. G. and Weber, E. U.: Perceptions and communication strategies for the many uncertainties relevant for climate policy, Wiley Interdisciplinary Reviews: Climate Change, 5, 219-232, doi:10.1002/wcc.259, 2014.

Pielke, R.: The honest broker:making sense of science in policy and politics, Cambridge University Press, Cambridge, 2007.

Ropeik, D.: The L'Aquila verdict: a judgment not against science, but against a failure of science communication, Scient. Am., http://blogs.scientificamerican.com/guest-blog/ (last access: June 2015), 2012.

Scolobig, A., Komendantova, N., Patt, A., Vinchon, C., MonfortCliment, D., Begoubou-Valerius, M., Gasparini, P., and Di Ruocco, A.: Multi-risk governance for natural hazards in Naples and Guadeloupe, Nat. Hazards, 73, 1523-1545, doi:10.1007/s11069-014-1152-1, 2014a.

Scolobig, A., Mechler, R., Komendantova, N., Wei, L., Schröter, D., and Patt, A.: The co-production of scientific advice and decision making under uncertainty: lessons from the 2009 L'Aquila earthquake, Italy, Planet. Risk, 2, 71-76, 2014b.

Scolobig, A., Prior, T., Schröter, D., Jörin, J., and Patt, A.: Towards people-centred approaches for effective disaster risk management: Balancing rhetoric with reality, Int. J. Disast. Risk Reduct., 12, 202-212, 2015.

Sharma, U. and Patt, A.: Disaster warning response: the effects of different types of personal experience, Nat. Hazards, 60, 409423, doi:10.1007/s11069-011-0023-2, 2012.
Sharma, U., Scolobig, A., and Patt, A.: The effects of decentralization on the production and use of risk assessment: insights from landslide management in India and Italy, Nat. Hazards, 64, 13571371, doi:10.1007/s11069-012-0300-8, 2012.

Siegrist, M.: More questions than answers: a response to 'Four questions for risk communication', J. Risk Res., 17, 1241-1243, doi:10.1080/13669877.2014.913668, 2014.

Sterett, S.: Disasters and socio-legal studies, Q. P. Books, New Orleans, 2013.

Studdert, D., Mello, M. M., Sage, W. M., DesRoches, C. M., Peugh, J., Zapert, K., and Brennan, T.,: Defensive medicine among high-risk specialist physicians in a volatile malpractice environment, J. Am. Med. Assoc., 293, 2609-2617, doi:10.1001/jama.293.21.2609, 2005.

Thompson, M.: Organizing and Disorganizing: A Dynamic and Non-Linear Theory of Institutional Emergence and Its Implications, Triarchy Press, London, 2008.

UNISDR: Global Risk Assessment Report, Geneva, 2015.

Van Der Sluijs, J. P., Craye, M., Funtowicz, S., Kloprogge, P., Ravetz, J., and Risbey, J.: Combining Quantitative and Qualitative Measures of Uncertainty in Model-Based Environmental Assessment: The NUSAP System, Risk Analysis, 25, 481-492, doi:10.1111/j.1539-6924.2005.00604.x, 2005.

White House: The Federal Response to Hurricane Katrina Lessons Learned, Washington, 2006.

Wyss, M. and Peppoloni, S. (Eds.): Geoethics: Ethical Challenges and Case Studies in Earth Science, Elsevier, Waltham, Massachusetts, 2015. 